\title{
ISCHAEMIC HEART DISEASE AND SUDDEN DEATH, 1901-61
}

\author{
T. W. ANDERSON, M.A., B.M. (Oxon), Ph.D., D.I.H. (Toronto) \\ Assistant Professor \\ AND \\ W. H. LE RICHE, B.Sc., M.D. (Witwatersrand), M.P.H. (Harvard) \\ Professor and Head \\ Department of Epidemiology and Biometrics, University of Toronto, Canada
}

SEVERAL distinguished authorities have recently questioned the widely held belief that death rates from ischaemic heart disease (IHD) have increased during the present century. Robb-Smith (1967) has devoted a monograph to the subject and concludes that the evidence in favour of any real increase is very insubstantial. He believes that the apparent increase in IHD mortality in England and Wales can be entirely explained by the ageing of the population and by the changes in medical terminology which have taken place during the past few decades. Similar conclusions have been reached by Campbell (1963a, b) and Bedford (1968) in Britain, and by Moriyama and Woolsey (1951) and Lew (1957) in the United States.

The resolution of this controversy is of more than academic interest, since a substantial part of the current large-scale effort to control IHD through public health education and aetiological research is based on the belief that some modern factors in our way of life are responsible for the present 'epidemic'.

We have therefore re-examined the evidence provided by death certificates, taking care to avoid the pitfalls documented by Robb-Smith and the other critics. Our study has been restricted to deaths occurring among men aged 45 to 64 in the Province of Ontario between 1901 and 1961, and we have based our conclusions on information obtained from original death certificates, on the records of the Toronto chief coroner's office, and on the official mortality tabulations of the Registrar General of Ontario.

Mortality records based on death certificates have often in the past proved to be an unsatisfactory method of studying trends in IHD mortality, because of the uncertainty surrounding the diagnosis of this condition (particularly in the early years of the century) and because of the frequent changes which have taken place in the international classification of causes of death, on which most official mortality tabulations are based. Blockage of a coronary artery by a thrombosis or an embolus was well recognized as a cause of sudden death by the end of the nineteenth century (Osler, 1895), but it was not until after the reports of Herrick $(1912,1919)$ that non-fatal coronary thrombosis came to be recognized as the underlying lesion in many cases of 'myocarditis' or 'fatty degeneration of the heart'. In any retrospective study it is therefore necessary to take account of these changes in medical terminology if misleading conclusions are to be avoided (Stewart, 1950; Platt, 1951).

In addition to errors resulting from a lack of knowledge of ischaemic heart-disease in the past, errors may also have occurred in the diagnoses appearing on death certificates as a result of the physican's misinterpretation of symptoms and physical signs. Thus dyspnoea of cardiac origin may sometimes have been ascribed to bronchial asthma, ankle oedema to Bright's disease (chronic nephritis), substernal pain to indigestion, and sudden death to apoplexy or cerebral haemorrhage. Rheumatic and syphilitic heart disease may also have been overdiagnosed in the past at the expense of ischaemic heart disease (Campbell, 1963a, b).

We have attempted to circumvent some of these problems by using three definitions of ischaemic heart disease. First, a narrow definition of 'pure' IHD in which only terms such as angina pectoris, arteriosclerotic heart disease, and coronary thrombosis were accepted. Second, a somewhat broader definition in which, in addition to the preceding terms, certain non-specific diagnoses were accepted such as heart failure, myocarditis, cardiac dropsy, and organic heart disease. Third, a very broad definition in which rheumatic heart disease, chronic nephritis, cardio-renal disease, asthma, indigestion, hypertension, and apoplexy were included. It was hoped that the first and third of these definitions would provide a form of lower and upper probability limit for the true rate of IHD mortality, and that over the years there might be common trends in all three definitions which would enable valid conclusions to be drawn.

To ensure that the death rates calculated for each of these definitions were undistorted by the periodic variations in the international classification of causes of death, we have worked with original death 
certificates rather than with the official mortality tabulations. This method has the disadvantage that rates are necessarily based on relatively small numbers, since manual searching of death certificates is a tedious and time-consuming process but is, we believe, compensated for by the elimination of much of the uncertainty present in the standard tabulations.

An added advantage of working with original death certificates was that it enabled us to study changes in the frequency with which sudden death was reported on death certificates over the years. A special committee of the World Health Organization (1959) has pointed out that the rate of sudden death in a community might provide a useful index of the prevalence of ischaemic heart disease in situations where diagnostic information is unreliable, since IHD is the commonest cause of sudden death in middle-aged men (Spain, Bradess and Mohr, 1960). We have attempted to test the validity of this suggestion by comparing trends in the rate of sudden death with the trends in rate shown by our three definitions of IHD. All cases of sudden death have been included in the calculations, excluding only those which were clearly unrelated to any form of cardiovascular disease.

As a check on the validity of the trends found in the reporting of sudden death on death certificates we have also examined the rate at which deaths were reported to the Toronto coroner's office between 1931 and 1961.

\section{Cardiac Deaths}

\section{Materials AND Methods}

A sample of Ontario death certificates was examined from each of the census years (ending in 1) between 1901 and 1961. The number of certificates examined from each year ranged between 2,500 and
5,000 (Table I), each annual sample being composed of three to five subsamples drawn from different geographical regions of the province, in which the proportions of urban and rural population were similar to that for the province as a whole. Full details of this method of sampling will be provided by the authors on request.

Diagnostic and other information was recorded from all those certificates in which the patient was a man aged between 45 and 64 , and in which any of the following diagnoses appeared in part I of the certificate, or, in earlier years, as the 'primary' cause of death:

Ischaemic heart disease (angina pectoris, coronary thrombosis, myocardial infarction, arteriosclerotic heart disease, etc.).

Non-specific heart disease (heart failure, cardiac dropsy, organic heart disease, myocarditis, etc.).

Possible ischaemic heart disease (Bright's disease, chronic nephritis, rheumatic heart disease, syphilitic cardiovascular disease, hypertension, asthma, acute indigestion, etc., plus cerebrovascular diagnoses of one hour duration or less).

After allowing for the size of the sample of death certificates studied, the death rate per 100,000 population was calculated, using the census figures for the population of men aged 45-64. The use of a 20-year age group rather than the conventional 10-year age group was made possible by the remarkable stability of the age distribution of middle aged men in Ontario during the past half century. In both 1901 and $1931,40.6 \%$ of the $45-64$ year age group was aged 55-64, and even in 1961 the proportion had risen only to $41.2 \%$. The mean age for the 45-64 year age group was 53.88 in 1901, 53.69 in 1931 , and 53.90 in 1961 . In the following example, standardization of the 1901 rate to the 1961

\section{TABLE I}

SAMPLE SIZE, NUMBER OF POSSIBLE IHD DEATHS IN SAMPLE, AND ESTIMATED RATES PER 100,000: MEN 45-64, 1901-6

\begin{tabular}{|c|c|c|c|c|c|c|c|}
\hline & 1901 & 1911 & 1921 & 1931 & 1941 & 1951 & 1961 \\
\hline Sample size (certificates examined) & 5,000 & 3,000 & 3,000 & 3,000 & 2,500 & 2,500 & 2,500 \\
\hline $\begin{array}{l}\text { Diagnostic categories* } \\
\text { (1) Ischaemic heart disease } \\
\text { (2) Non-specific heart disease } \\
\text { (3) Other possible ischaemic heart disease }\end{array}$ & $\begin{array}{r}2 \\
54 \\
50\end{array}$ & $\begin{array}{l}11 \\
38 \\
44\end{array}$ & $\begin{array}{l}16 \\
32 \\
40\end{array}$ & $\begin{array}{l}39 \\
26 \\
33\end{array}$ & $\begin{array}{l}89 \\
22 \\
13\end{array}$ & $\begin{array}{r}136 \\
18 \\
29\end{array}$ & $\begin{array}{r}194 \\
3 \\
19\end{array}$ \\
\hline $\begin{array}{c}\text { Rates/100,000 population } \\
\text { Category } 1+2 \\
1+2+3 \\
1+2\end{array}$ & $\begin{array}{r}7 \\
200 \\
378\end{array}$ & $\begin{array}{r}60 \\
268 \\
508\end{array}$ & $\begin{array}{r}70 \\
211 \\
388\end{array}$ & $\begin{array}{l}142 \\
237 \\
357\end{array}$ & $\begin{array}{l}350 \\
436 \\
489\end{array}$ & $\begin{array}{l}518 \\
586 \\
698\end{array}$ & $\begin{array}{l}681 \\
692 \\
759\end{array}$ \\
\hline 'Diseases of Circulation' (based on official mortality data) & $t$ & $t$ & 275 & 381 & 526 & 672 & 654 \\
\hline
\end{tabular}

-Diagnostic categories are defined in Materials and Methods

tSuitable data were not available for these years. 
age distribution would cause only a slight change in rate, from 378 to 380 per 100,000 .

\section{Example (1901)}

Total certificates for year (both sexes, all ages): 29,608

Sample size: 5,000

Total 'cardiac' deaths (men 45-64) in sample: 106

Estimated total 'cardiac' deaths during year: $106 \times 29,608 / 5,000(=628)$

Census population (men 45-64): 166,077

Rate $=628 \times 100,000 / 166,077(=378$ per 100,000)

\section{Sudden Deaths}

Rates of sudden death in men aged 45-64 were obtained in essentially the same way as described for cardiac deaths. In the earlier years, because of the small number of sudden deaths encountered in the original samples, the sample size was increased, in some cases up to approximately 10,000 certificates (Table II). The form of certificate in use around 1941 did not request, or provide space for, information on duration of illness, and this year has therefore been omitted from the calculations.

Details were recorded from every certificate in which death was ascribed to natural causes (i.e., not accident, suicide, etc.) and in which death was said to have been 'sudden', irrespective of the diagnosis appearing on the certificate.

Initially, our definition of sudden death was broadened to include those deaths in which the duration of final illness was said to be one hour or less. However, it was found that the number of such deaths fluctuated widely, according to the form of certificate in use at the time. Thus in recent years many certificates contained several durations, e.g., 'arteriosclerotic heart disease-5 years; coronary thrombosis-3 days; second attack-10 minutes'. In earlier years, when there was only space on the certificate for the cause of death, such a sequence might have been shortened to "heart disease-5 years', or 'acute heart failure-3 days', thus reducing the apparent frequency of 'sudden' death. The use of the word 'sudden' on a certificate implies not only that death was preceded by an illness of short duration but that it was unexpected, and such information appears to have been less affected by the form of certificate in use at the time. Furthermore, rates based on this definition of sudden death are more likely to be comparable to rates obtained from coroners' records.

Diagnoses were grouped into the following categories (the first two of which are the same as those used for total cardiac deaths):

Ischaemic heart disease (angina pectoris, coronary thrombosis, etc.)

Non-specific heart disease (heart failure, myocarditis, etc.)

Rheumatic and other heart disease (valvular disease, syphilitic disease of heart, etc.)

Cerebrovascular disease (apoplexy, cerebral haemorrhage, etc.)

Nephritis, hypertension (Bright's disease, cardiorenal disease, etc.)

Miscellaneous (pulmonary embolus, ruptucu aortic aneurysm, acute indigestion, etc.)

Clearly not heart disease (haemorrhage due iv pulmonary tuberculosis, cancer of the tongue, etc.)

Rates were calculated as previously described, using the census figures for population at risk and adjusting for the size of the sample of death certificates examined.

An adjusted rate was also calculated for each year. This adjusted rate was based on the assumption that

TABLE II

SAMPLE SIZE, NUMBER OF SUDDEN DEATHS IN SAMPLE, AND ESTIMATED RATES PER 100,000: MEN 45-64, 1901-61

\begin{tabular}{|c|c|c|c|c|c|c|}
\hline & 1901 & 1911 & 1921 & 1931 & 1951 & 1961 \\
\hline Sample size (certificates examined) & 9,816 & 9,358 & 9,377 & 5,123 & 2,500 & 2,500 \\
\hline $\begin{array}{l}\text { Ischaemic heart disease } \\
\text { Non-specific heart disease } \\
\text { Rheumatic and other heart disease } \\
\text { Cerebrovascular disease } \\
\text { Nephritis, hypertension } \\
\text { Miscellaneous (pulmonary embolus, ruptured aortic aneurysm, etc.) } \\
\text { Clearly not heart disease }\end{array}$ & $\begin{array}{l}\overline{6} \\
2 \\
\frac{2}{0} \\
\overline{0}\end{array}$ & $\begin{array}{r}1 \\
15 \\
4 \\
2 \\
2\end{array}$ & $\begin{array}{r}\overline{21} \\
\frac{3}{4} \\
\frac{4}{2}\end{array}$ & $\frac{12}{1}$ & $\begin{array}{r}25 \\
\frac{2}{2} \\
\frac{2}{1}\end{array}$ & $\frac{25}{-\frac{2}{2}}$ \\
\hline Total (excluding 'clearly not heart disease') & 10 & 22 & 32 & 20 & 29 & 27 \\
\hline $\begin{array}{c}\text { Rate per } 100,000 \text { —unadjusted } \\
\text { —adjusted }\end{array}$ & 18 & $\begin{array}{l}39 \\
48\end{array}$ & $\begin{array}{l}45 \\
68\end{array}$ & $\begin{array}{l}42 \\
57\end{array}$ & $\begin{array}{l}110 \\
124\end{array}$ & $\begin{array}{r}95 \\
119\end{array}$ \\
\hline
\end{tabular}

-Adjusted for those certificates showing no information on duration of illness 
those certificates on which no information concerning duration was recorded had the same proportion of sudden deaths as those certificates on which duration was recorded. Thus, in 1901 only $57 \%$ of cardiac certificates carried information on duration, and the adjusted rate for this year was therefore $18 \times 100 / 57,=32$ per 100,000 .

In the other years the proportion of cardiac certificates showing duration was $82 \%(1911), 66 \%$ (1921), 78\% (1931), 89\% (1951) and 80\% (1961).

\section{Deaths Reported to the Coroner}

Ideally coroners' records for the whole province should have been studied, since the sampling of death certificates was done on a province-wide basis. However, provincial statistics on coroners' cases are only available since 1962, and we have therefore used data from the city of Toronto, where records have been maintained since 1928 . Toronto death rates have, for many years, been somewhat higher than those for the rest of the province but this differential changed little between 1931 and 1961, and it is therefore likely that provincial trends will have been reflected in the Toronto figures.

From the coroners' records details were obtained of all deaths ascribed to natural causes occurring in men aged 45 to 64 for several complete years between 1931 and 1961 (Table III). Diagnoses were divided into two groups, the first of which corresponds to the first two categories used in total cardiac deaths.

Ischaemic and non-specific heart disease (angina pectoris, coronary thrombosis, etc.)

All other disease deaths (excluding deaths from violence).

Census figures for the male population of Toronto aged 45 to 64 were used to calculate rates per 100,000 in census years $(1931,1941$, etc.) and census-based estimates of this population were used to calculate rates in intercensal years. Deaths occurring in nonresidents were not separated from those occurring in residents, since the number of non-residents was small (about $4 \%$ of total) and showed little variation from year to year.
The regression line for the death rates between 1936 and 1951 was based on regression equations calculated by the standard method of 'least squares' (Snedecor, 1956).

\section{RESULTS}

The changes in death rates may be examined most conveniently in two stages, from 1901 to 1931 and from 1931 to 1961 . The trends since 1931 are the least ambiguous and will therefore be considered first.

\section{1-61}

Death rates based on all three definitions of ischaemic heart disease showed a marked rise during this period (Table I and Fig. 1). For the narrowest definition ('pure' IHD, Table I, category 1) the rates rose from 142 to 681 per 100,000 while for

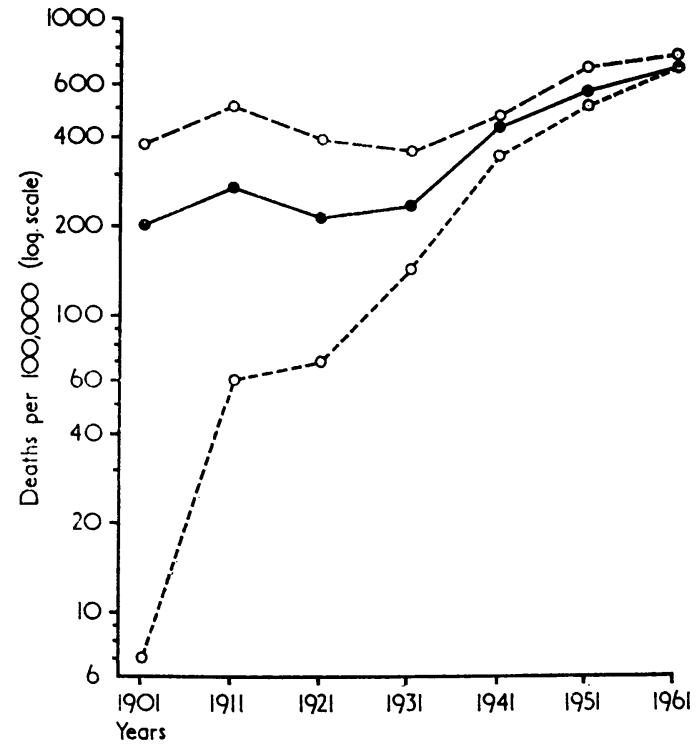

FIG. 1.-Death rates per 100,000 according to three definitions of ischaemic disease, men 45-64, 1901-61: 0 - - - - O'pure' ischaemic heart disease; 0 all possible ischaemic heart disease.

TABLE III

RATES PER 100,000 AT WHICH DEATHS WERE REPORTED TO CORONERS IN THE CITY OF TORONTO: MEN 45-64, 1931-61

\begin{tabular}{l|r|r|r|r|r|r|r|r|r|}
\hline $\mathrm{N}^{*}$ & 1931 & 1936 & 1939 & 1941 & 1947 & 1949 & 1951 & 1961 \\
\hline (1) Ischaemic and non-specific heart disease & 145 & 223 & 279 & 311 & 395 & 420 & 399 & 512 \\
\hline (2) All other disease deaths & 170 & 184 & 255 & 272 & 360 & 408 & 369 & 542 \\
\hline Total & 86 & 129 & 133 & 128 & 148 & 128 & 126 & 188 \\
\hline
\end{tabular}

$\bullet \mathbf{N}=$ total number of deaths reported. 
the broadest definition (all possible IHD, Table I, categories 1 to 3 ) the rate rose from 357 to 759 per 100,000 . If the true IHD rate can be assumed to lie somewhere between these two extremes, then the increase in rate must have been at least of the order of 1.9:1 (from 357 to 681 per 100,000).

During the same period the sudden death rates based on death certificates more than doubled, the unadjusted rate rising from 42 to 95 per 100,000 and the adjusted rate from 57 to 119 per 100,000 (Table II and Fig. 2). The increase in both rates occurred entirely during the first 20 years, and the rates then declined slightly between 1951 and 1961 .

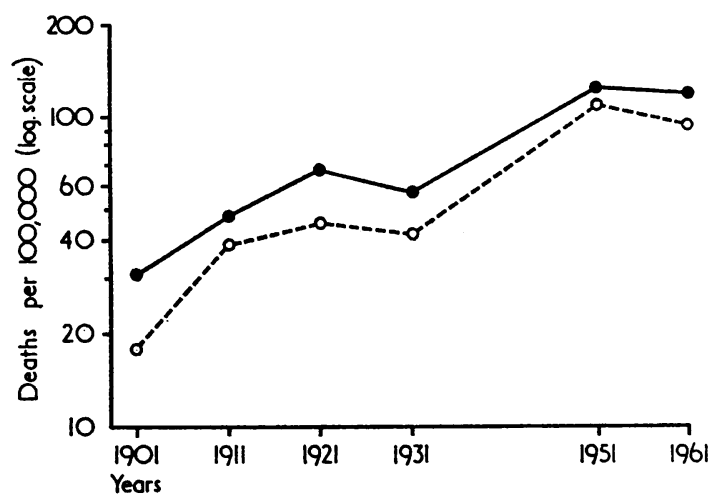

Fio. 2.-Rates per 100,000 for deaths reported as 'sudden' on death certificates, men 45-64, 1901-61: $0-1-\ldots$ - O unadjusted rate; no information on duration of illness.

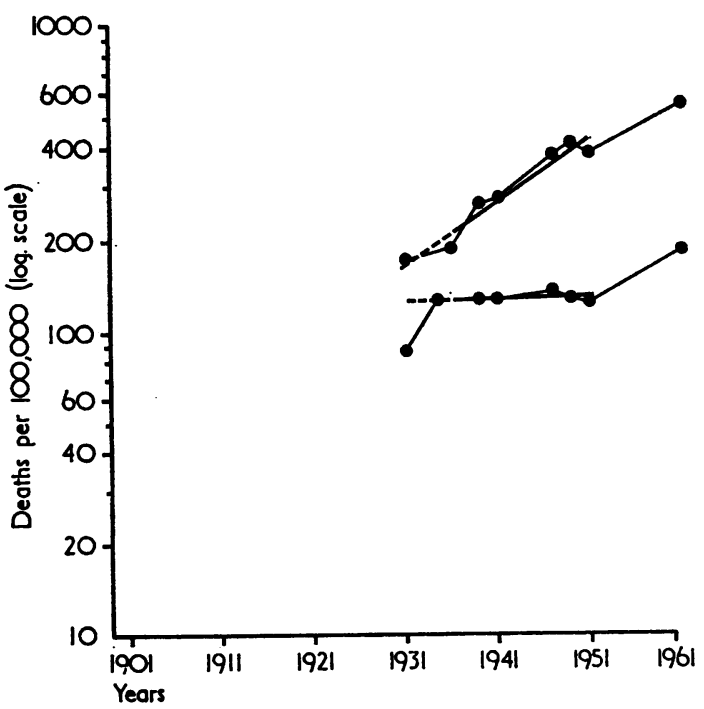

Fio. 3.-Rates per 100,000 at which deaths were reported to coroners in the city of Toronto, men 45-64,1931-61. Regression lines have been calculated on the data from 1936 to 1951 and are extrapolated been calculated on the data from 1936 to 1951 and are extrapolated
back to 1931 . Upper line-deaths ascribed to ischaemic and nonspecific heart disease: Lower line-all other disease deaths.
Similarly, the rate at which deaths from natural causes were reported to the Toronto coroner's office rose from 256 per 100,000 in 1931 to 630 per 100,000 in 1961 (Table III and Fig. 3). The increase was due largely to deaths ascribed to ischaemic and non-specific heart disease, which rose from 170 to 542 per 100,000 during this period. In $193157 \%$ of these diagnoses were specific for ischaemic heart disease, and by 1961 the proportion had risen to $99 \%$. These figures must, however, be interpreted with caution, since a change in the rate at which deaths are reported to the coroner may result from a change in reporting policy, as well as from a change in the incidence of disease. This problem may be overcome to some extent by using the rate for noncardiac conditions as a control and restricting the study of heart disease deaths to a period when the reporting rate for these other conditions was stable. Such a situation existed between 1936 and 1951, during which time the rate for non-cardiac conditions showed virtually no change, while the rate for deaths due to ischaemic and non-specific heart disease rose from 184 to 369 per 100,000 . A regression line has been calculated on the rates for the years 1936 to 1951 and extrapolated back to 1931 to give an estimated reporting rate in that year of 164 per 100,000. For 1951 the regression line estimate of the death rate was 428 per 100,000 , which is 2.6 times the 1931 figure. For other disease deaths the extrapolated regression line shows a barely perceptible rise, from 125 per 100,000 in 1931 to 130 per 100,000 in 1951.

The absolute values of the sudden death rates based on death certificate information were considerably lower than those based on coroners' records. For example, in 1951 even the adjusted death certificate rate $(124$ per 100,000$)$ was only a quarter of the coroner's rate $(495$ per 100,000$)$. This suggests that sudden death was under-reported on death certificates, but presumably the degree of under-reporting was similar in 1931 and 1951, so that the proportional increase in rates was unaffected. Whether the degree of under-reporting on death certificates remained the same between 1951 and 1961 cannot be determined since the general rise in the coroners' reporting rate during this period limits the usefulness of these figures as a source of confirmatory data. It is therefore uncertain whether the rising incidence of sudden deaths continued after 1951, or whether (as indicated in Fig. 2) the incidence declined.

An additional source of uncertainty concerning all the rate changes observed in this study is the relatively large degree of random variation which may occur in estimates based on small samples. The poten- 


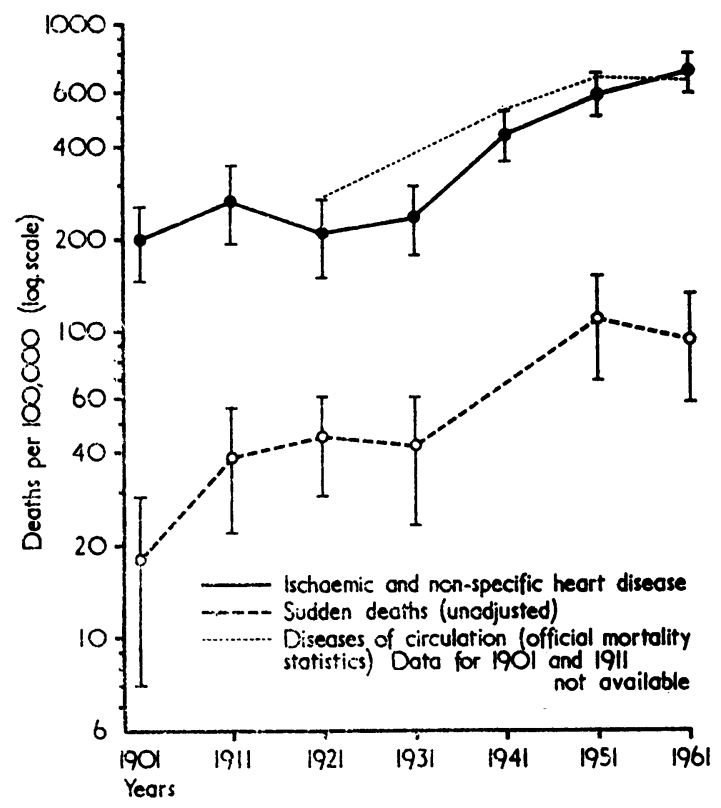

Fig. 4.-Death rates per 100,000 and $95 \%$ confidence limits of sample estimates.

tial seriousness of this source of error may be judged from Fig. 4, in which the rates for the intermediate definition of IHD (ischaemic and non-specific heart disease) and for sudden death (unadjusted) have been plotted together with their $95 \%$ confidence limits. These limits are based on \pm 2 standard deviations, the standard deviation being calculated from the formula: Rate $/ \sqrt{ } N$ (where $N$ is the number of observations).

It is evident that the small changes in rate which occurred between 1951 and 1961 may well be due to sampling error, but it is equally clear that the large increases between 1931 and 1951 are very unlikely to be due to this effect.

Confirmation that a substantial increase occurred in the male cardiovascular death rate between 1931 and 1951 is provided by the official mortality tabulations of the Registrar General of Ontario. The death rate due to all diseases of the heart among men aged 45 to 64 rose from 295 per 100,000 in 1931 to 638 per 100,000 in 1951. A major revision of the international classification occurred in 1950 , so that part of the increase might be attributed to this change, but even by 1949, which was the last year of the old classification, the death rate had reached 612 per 100,000 . The death rate from all diseases of the circulatory system showed a similar trend, rising from 381 per 100,000 in 1931 to 626 per 100,000 in 1949 , to 672 per 100,000 in 1951.
The similarity of the increases in rate shown by these various indices of cardiac mortality is evident in Table IV. In the light of these figures the con-

TABLE IV

SOURCES OF INFORMATION, DEATH RATES PER 100,000, AND RATIO OF 1951 TO 1931 RATES: MEN 45-64

\begin{tabular}{l|r|r|r}
\hline & \multicolumn{3}{|c|}{ Death Rate per 100,000 } \\
\cline { 2 - 4 } & 1931 & 1951 & $1951 / 1931$ \\
\hline & & & \\
\hline Death certificate sampling & 142 & 518 & 3.6 \\
Pure' IID & 237 & 586 & 2.5 \\
IHD + non-specific heart disease & 357 & 698 & 2.0 \\
All possible IHD & 42 & 110 & 2.6 \\
Sudden death—unadjusted & 57 & 124 & 2.2 \\
\hline Coroners' cases (regression estimate) & 164 & 428 & 2.6 \\
\hline Registrar-General annual report for & & & \\
$\quad$ Ontario & & & \\
Diseases of heart & 295 & 638 & 2.2 \\
Diseases of circulatory system & 381 & 672 & 1.8 \\
\hline
\end{tabular}

clusion seems inescapable that mortality from heart disease among middle-aged men in Ontario approximately doubled during the 20-year period 1931 to 1951. Since the rate from the other major forms of heart disease declined during this time (Friedberg, 1966) the increase was almost certainly due to arp increase in ischaemic heart disease mortality.

Between 1951 and 1961 the evidence of an increase in IHD is much less convincing. According to ou sample estimates, there was an increased rate for all three definitions of IHD (Fig. 1), but the increase was smaller than that seen in the previous two decades and was well within the $95 \%$ limits of sample error. Official mortality figures during this period showed a slight decrease in the rate for all diseases of the heart, from 638 to 629 per 100,000 and in the rate for all diseases of the circulatory system, from 672 to 654 per 100,000 . It seems probable therefore that there was little or no change in the IHD death rate after 1951, and the trend shown by our sudden death rates (Fig. 2) is consistent with this view.

\section{1-31}

There is no clear evidence of an upward trend in IHD mortality before 1931 . The death rate for our narrowest definition of ischaemic heart disease rose by a factor of 20 between 1901 and 1931 (Table I and Fig. 1), but neither of the broader definitions showed any consistent trend, and the fluctuations which did occur in these rates were well within the limits of sample variation (Fig. 4).

If the death rate at which sudden deaths were reported on death certificates can be taken as a valid index of total IHD mortality, then the latter must have doubled during this period. However, as previously discussed, there appears to be con- 
siderable under-reporting of sudden deaths on death certificates, and a relatively small variation in the certifying habits of physicians could well be responsible for the doubling of the sudden death rate over this 30-year period.

At the same time a twofold increase in the IHD death rate between 1901 and 1931 cannot be ruled out, since such an increase is well within the range of increase shown by our limiting definitions of IHD. It could be argued that the failure of either of the broad definitions to show an increase during this period was due to a rising IHD rate being obscured by a simultaneous decline in the death rate from rheumatic and other cardiac disorders. In the absence of reliable information on the relative frequency of ischaemic and non-ischaemic heart disease during this time no firm conclusion can be reached.

\section{Discussion}

Previous attempts to demonstrate an increase in IHD mortality on the basis of death certificate information have been confined to studies using routinely published mortality data. No direct comparison can therefore be made between these earlier studies and that part of our investigation which was based on death certificate sampling and the examination of coroners' records. However, the rise in death rate which we have found to have taken place between 1931 and 1951 was, as already pointed out, reflected in the official Ontario figures for diseases of the heart and of the circulatory system. We may therefore reasonably expect to find evidence of a similar rise in the published mortality rates of other countries, unless this increase was a local phenomenon confined to Ontario.

An examination of mortality data from England and Wales reveals that there has indeed been an increase of similar magnitude in the death rates for diseases of the heart and circulatory system during the century but that it may have occurred earlier than in Ontario, between 1920 and 1940.

Campbell (1963a, b), working with crude rates (both sexes, all ages), found that the death rate from all diseases of the heart rose from 1,406 per 100,000 in 1920 to 3,416 per 100,000 in 1940 . He recognized that there had been only minor changes in the international classification of causes of death during this time and went to some lengths to account for this increase in terms of a rise in the number of persons reaching middle age. This explanation is unconvincing, however, since there should be no increase in the death rate (per 100,000 living) at any age simply as a result of an increase in the total number of persons surviving to that age.
Robb-Smith (1967) avoided the confusion inherent in the use of crude death rates by working with a limited age group, 45 to 75 . Unfortunately, he did not separate male and female death rates, but nonetheless he also observed that there had been a large rise in the cardiac death rate in England and Wales between 1920 and 1939. Prior to 1920 the death rate from all diseases of the heart in this age group had been falling, but in the subsequent 19 years it rose from 212 to 511 per 100,000 . After 1939 the rate was relatively stable, and Robb-Smith bases his conclusions that no real increase in IHD has occurred in recent years on the stability of this rate, pointing out that the apparent increase in IHD since 1939 is simply the result of changing terminology within the heart disease classification. However, he provides no real explanation of the change in rate between 1920 and 1939, dismissing it as consequent on procedural changes, although the changes which occurred about this time were minor and had little effect on total cardiac death rates (Campbell, 1963a, b).

It may also be significant that in England and Wales the death rate from all causes fell steadily from 1900 to 1902 , changed little between 1920 and 1940, and then resumed its downward trend (Morris, 1960; Robb-Smith, 1967). This is compatible with the belief that the rise in death rate due to heart disease between 1920 and 1940 was not just a statistical artefact, resulting from a re-classification of causes of death, but that it was a real increase, substantial enough to interrupt the decline in total death rate from all causes.

In the United States the cardiac death rate during this century has risen less abruptly than it has in Ontario or in England and Wales. The age-adjusted death rate from all diseases of the heart rose from 177 per 100,000 in 1900 , to 244 per 100,000 in 1920 , to 340 per 100,000 in 1940 (Woolsey and Moriyama, 1948). Since 1940 there appears to have been no further increase in these rates (Lew, 1957). It must also be borne in mind that IHD rates may have been rising in the United States before 1900, since Osler (1910) commented that consultants in that country had the impression that angina pectoris had lately become more common.

\section{Sudden Death as an Index of Ischaemic Heart DiseASE}

The W.H.O. Expert Committee on Cardiovascular Diseases and Hypertension (1959) suggested that sudden death might provide a useful index of the frequency of ischaemic heart disease but recognized that more research was needed to test the validity of this approach. 
There are several difficulties in using sudden death in this way. First, the definition of sudden death must be the same in the communities studied. Not only must the duration of final illness be clearly defined (Kuller, 1966), but there must also be agreement on the degree to which death should be unexpected in order to be termed sudden. (For example, should a death be classified as sudden even though there is a previous history of severe ischaemic heart disease?)

A second difficulty, which has already been mentioned in connection with the rising trend of sudden death in Ontario males between 1901 and 1931 , is the possibility that differences in the completeness with which sudden death is reported could give rise to apparent differences in the sudden death rate. Unless it is known for certain that reporting is complete (or is incomplete to exactly the same extent), comparisons in time or place could be misleading.

The third, and in some respects most serious, obstacle to the use of sudden death as an index of ischaemic heart disease is that it is based on the assumption that IHD is not only the most common cause of sudden death, but that the proportion of total IHD deaths which occur suddenly is fixed.

The first part of this assumption, that most sudden deaths are due to IHD, may well be true at the present time in developed countries (Spain et al., 1960), but it may not have been true in the past, and may still not be true in some other parts of the world.

The second part of the assumption is also open to question, since it is theoretically possible that an environmental factor could, by altering the level of myocardial excitability, cause an increased incidence of sudden death from ventricular fibrillation and other cardiac arrhythmias. If the non-sudden IHD death rate remained unaffected by this change in myocardial excitability, there would then be a rise in the total IHD death rate and an increase in the proportion of these deaths which occurred suddenly.

Such a mechanism might well account for our recent observation (Anderson, le Riche, and MacKay, 1969) that in Ontario the sudden death rate varies inversely with the hardness of the local water supply, while the non-sudden IHD death rate does not appear to be related to water hardness.

A selective increase in sudden death due to cardiac arrhythmias has also been put forward as a possible explanation of the paradox that a rise in the death rate due to 'coronary thrombosis' may have occurred during this century without any comparable rise in the death rate due to cerebral thrombosis (Anderson and MacKay, 1968). However, our present results suggest that this is an unlikely explanation of the increase in IHD mortality which occurred in this province between 1931 and 1951, since the trends in rate for total deaths and sudden deaths were parallel during this period (Figs. 1, 2 and 4). This suggests that there was not a selective increase in sudden death, but rather an overall increase in the incidence of fatal myocardial infarctions, among which the proportion of sudden deaths remained unchanged.

It would appear therefore that, by itself, sudden death may not be a reliable index of IHD mortality, although in a restricted population and over a limited period of time it can provide useful confirmatory evidence of trends in the IHD death rate based on diagnostic information.

\section{SUMMARY}

The evidence in favour of a rising incidence of ischaemic heart disease (IHD) during this century has been re-examined for men aged 45 to 64 in the province of Ontario.

To reduce the possibility that change in rate may reflect changing terminology rather than changing incidence, several definitions of ischaemic heart disease have been used, and rates have been based on samples of original death certificates rather than on official mortality tabulations. In addition, rates of sudden death have been examined, using both deatho certificate information and coroners' records for the? city of Toronto. Between 1931 and 1951 all three rates increased by at least $100 \%$, suggesting that a genuine increase in IHD mortality occurred during this time.

The usefulness of sudden death as an index of ischaemic heart disease is discussed, and attention is drawn to the similarity between the rise in the cardiac death rate in Ontario between 1931 and 1951 and that which occurred in England and Wales between 1920 and 1940.

We wish to thank Mr. H. F. C. Humphries, deputy Registrar-General of the province of Ontario, and Mr. J. Wagner, coroner's chief clerk of the city Toronto, for cooperation in this study. We are also grateful to D. Eaton and D. Blair for conscientious technical assistance. The investigation was supported by a Public Health Research Grant (P.R. 21) from the Department of Health of Toronto.

\section{REFERENCES}

Anderson, T. W., and MacKay, J. S. (1968). A critical reappraisal of the epidemiology of cerebrovascular disease. Lancet, 1, 1137.

, LE RICHE, W. H., and MaCKAY, J. S. (1969). Sudden death and ischemic heart disease: correlation with hardness of local water supply. New Engl. J. Med., 280, 805. 
BeDFORD, D. E. (1968). Harvey's third circulation. De Circulo Sanguinis in Corde. Brit. med. J., 4, 273.

Camprell, M. (1963a). Death rate from diseases of the heart: 1876 to 1959. Ibid., 2, 528. (1963b). The main cause of increased death rate from diseases of the heart: 1920 to 1959. Ibid., 2, 712.

FriedberG, C. K. (1966). Diseases of the Heart, 3rd ed., Saunders, Philadelphia and London.

HeRrick, J. B. (1912). Clinical features of sudden obstruction of the coronary arteries. J. Amer. med. Ass., 59, 2015.

(1919). Thrombosis of the coronary arteries. Ibid. 72, 387.

Kuller, L. (1966). Sudden and unexpected nontraumatic deaths in adults: a review of epidemiological and clinical studies. J. chron. Dis., 19, 1165.

LEw, E. A. (1957). Some implications of mortality statistics relating to coronary artery disease. Ibid., 6, 192.

Moriyama, I. M., and Woolsey, T. D. (1951). Statistical studies of heart disease. IX. Race and sex differences in the trend of mortality from the major cardiovascularrenal diseases. Publ. Hlth Rep. (Wash.), 66, 355.

MORRIS, J. N. (1960). Epidemiology and cardiovascular disease of middle age: Part I. Mod. Conc. cardiovasc. Dis., 29, 625.

OSLER, W. (1895). The Principles and Practice of Medicine. 2nd ed. New York.
(1910). The Lumleian lectures on angina pectoris: lecture I. Lancet, 1, 697.

Platt, R. (1951). Coronary disease and modern stress (letter to the editor). Ibid., 1, 51.

Registrar-General of ONTARIo, Annual Vital Statistics Reports, 1924-1961.

Roвb-Smith, A. H. T. (1967). The Enigma of Coronary Heart Disease. Year Book Medical Publishers, Chicago.

SNEDECOR, G. W. (1956). Statistical Methods. Iowa State University Press, Ames, Iowa.

Spain, D. M., Bradess, V. A., and Mohr, C. (1960). Coronary atherosclerosis as a cause of unexpected and unexplained death: an autopsy study from 1949-1959. J. Amer. med. Ass., 174, 384.

StewarT, I. MCD. G. (1950). Coronary disease and modern stress. Lancet, 2, 867.

WoOlsey, T. D., and Moriyama, I. M. (1948). Statistical studies of heart disease. II. Important factors in heart disease mortality trends. Publ. Hlth Rep. (Wash.), 63, 1247.

World Health Organization Expert Committee on Cardiovascular Diseases and Hypertension (1959). Hypertension and Coronary Heart Disease: Classification and Criteria for Epidemiological Studies. Techn. Rep. Ser. Wld Hlth Org. no. 168. 